\title{
An Investigation into the State of Environmental Education and the use of Technology in Environmental Education in Gauteng, South Africa
}

\author{
Scott Sanders and Thea Schoeman
}

\begin{abstract}
An investigation is undertaken into the state of environmental education (EE) and the use of technology in EE in Gauteng, South Africa. The marriage of technology and EE is the perfect tool to enhance the latter. However, the implementation of both within the South African schooling system is notably slow. The state of EE and how technology is used in the classroom are largely unknown within South Africa. This study investigated the views of educators regarding the current status of EE in schools and identified the challenges and barriers faced by educators in teaching $\mathrm{EE}$ and the use of technology.
\end{abstract}

Keywords - Environmental education, GIS, information and communication technologies, South Africa.

\section{INTRODUCTION}

Since the Industrial Revolution, humankind used and consumed the earth's resources for its own gain, but at the expense of the earth's biosphere [1], [2]. This resulted in numerous negative impacts on the environment [3], [4] that have not gone unnoticed in education. The roots of EE can be traced back to the $18^{\text {th }}$ century when Jean-Jacques Rousseau identified the importance of learning about the environment [5] and established one of the first EE programmes, namely 'Nature Study'.

It was not until 1995 that EE was listed as one of the key principles for education and training in South Africa in the $21^{\text {st }}$ century [6]. However, very limited research is available on EE in South Africa and the use of information and communication technologies (ICT) and geographical information systems (GIS) and its implementation in EE.

Since the 1970s, there have been exponential advances in technology - from automation to the use of mobile cellular

Manuscript received September 10, 2019.

Scott Sanders completed his MSc Environmental Management at the University of Johannesburg and is currently employed as an environmental scientist at Rayten Engineering Solutions, Johannesburg, South Africa.

Thea Schoeman is in the Department of Geography, Environmental Management \& Energy Studies, University of Johannesburg, Gauteng, South Africa. devices and the development of the internet. These advances had a significant impact on almost every sector, including the educational sector [7]. According to [8], technology can be of assistance in the field of education in two ways, namely in the removal of physical barriers to learning, and in the "transition of focus from the retention of knowledge to its utilization" [8:3]. In line with this, the marriage of technology and EE is a perfect tool to enhance the latter. However, the implementation of both within the schooling system is often slow, as in South Africa.

Even though EE has been included as key learning outcomes in all eight learning areas in the South African school curriculum [9], the status of the implementation of EE into school curricula [10] and the views of educators towards EE is not well known. The implementation of technological programmes such as ICT and GIS are perfectly aligned with the teaching of $\mathrm{EE}$ in the $21^{\text {st }}$ century. The importance of and potential for applying both GIS and ICT are recognised by the Department of Basic Education (DBE) in that both are included in one of the nine aims of the Geography syllabus for the FET phase [11]. This study therefore investigated the state of EE and the use of technology in teaching EE in the Further Education and Training (FET) phase of selected secondary schools in Gauteng.

\section{LITERATURE REVIEW}

Countries around the world - including South Africa - have made it an objective to implement EE into their respective schooling systems as a cross-curricular theme. This movement stems from key international conferences from which various resolutions were made and ratified to implement EE globally. As a result the South African government, as a signatory, has committed to addressing the global environmental crises through education [12].

Three stages of stages preceding modern EE were identified by [13], namely Rousseau's Nature Study, conservation education and outdoor education. Modern EE was influenced greatly by academics such as Robert Marshall (1901-1939) and Aldo Leopald (1887-1948) [14] that focused on the conservation of resources and the preservation of habitats. EE has since evolved and currently the focus is on the quality of the 
environment, environmental awareness, and environmental literacy [14].

It was in 1969 that the first definition of EE appeared in the Journal of Environmental Education. The definition provided by $[15: 1]$ is: "EE is aimed at producing a citizenry that is knowledgeable concerning the biophysical environment and its associated problems, aware of how to help solve these problems and motivated to work towards their solution". EE gained global recognition through the United Nations Conference on the Human Environment held in Stockholm in 1972 where a declaration was mandated that EE had to be applied as a tool to address global environmental problems [5]. EE's place on the world stage was cemented through two further conferences in 1975 and 1977. The first was the International Workshop on EE in Belgrade which produced the Belgrade Charter that laid out the goals, objectives, target audiences, as well as the guiding principles of EE [16]. The second conference was the first Intergovernmental Conference on EE held in Tbilisi, Georgia, whose outcome was the Tbilisi Declaration. This declaration laid out clear principles and objectives for the creation of environmental literate citizens and can be seen as the transition from traditional approaches of conservation towards sustainable development [17].

Almost every country around the world has embraced the ideologies surrounding EE over the past five decades [18]. However, the implementation of $\mathrm{EE}$ in respective national educational curricula have been met with varying levels of success.

\section{A. Environmental Education in South Africa}

Interest in EE in South Africa was first observed as early as the 1960s, where foundations were first laid by non-governmental and state-owned conservation agencies [19]. However, it was not until 1989 that attempts were made to include EE in nation-wide formal curricula. This came in the form of the 1989 White Paper on Environmental Education but was never enacted in the South African Parliament [17]. EE secured its place within the South African education system when EE was included in the 1995 Government White Paper on Education and Training in South Africa in the $21^{\text {st }}$ century. The principle recognized that $\mathrm{EE}$ is a vital link to the creation of environmentally literate and active citizens and to be used to ensure that all South Africans enjoy a decent quality of life through the sustainable use of resources, which is to be inter-disciplinary and integrated across all levels [20].

After South Africa's first democratic elections in 1994, education reform took place to restructure the school curricula. There have been several revisions of the national curricula since the mid-1990s, with the aim of creating a more holistic approach to learning [21]. One of the first revisions was Curriculum 2005 or C2005, a curriculum that was focused on life-long learning and was an intensively learner-centered pedagogy as opposed to a teacher-centered one [22]. It was during this period that the South African government introduced the National EE Programme (NEEP), marking the South African governments commitment to EE and the development of the discipline in South Africa [22]. The NEEP was seen to have two phases, the first was a research phase and the second a professional development phase for the development of educators [22].
There have been two further revisions of the national curricula since the introduction of C2005 with the aim of streamlining and making curricula more inclusive and accessible to both educators and students as well as to adjust to the demands of the $21^{\text {st }}$ century.

Literature concerning case studies of the implementation of EE within South African schools are limited and indicates that there is a lack of depth of literature concerning EE within South Africa. No literature could be found on the use of technology in EE in South Africa. With the onset of the fourth industrial revolution, the way we live and work is changing and if education does not change with it, the learners are at a serious disadvantage. There is thus a dire need to transform the way we educate and to introduce technology in classrooms.

\section{B. Use of Technology in Education in South Africa}

Around the world education systems have been experiencing significant changes owing to advancements in digital technology [23]. The range of technologies that are available to education systems has increased dramatically in recent years and can be viewed in different ways. When specifically looking at Geography as a subject and how technology can be used within its domain, there are three distinctions which can be made in terms of the types of technology. The first includes geospatial technologies, the second the application of GIS, and lastly, the use of geocaching in the teaching of Geography [24].

"The use of ICTs in education has the potential to add value to curricula and to transform students into knowledge constructors" [24:242] and can be used extensively in the teaching of EE. ICTs range from Microsoft PowerPoint to the use of digital sound clips, the use of platforms such as Google Earth, and even the use of smartboards in the classroom. A vital but often overlooked form of ICT incudes the internet [24]. GIS made its way into the secondary school environment over time and thus the realm of EE within secondary schooling. South Africa embraced GIS as a technology in the school curricula in 2006 when it was introduced in the Geography FET phase.

However, GIS has faced significant pedagogical, curricula, technological and infrastructural challenges when implemented into education systems around the world. Three challenges South Africa faced in terms of successfully implementing GIS into its national curricula were identified by [27] and include: money, support and time, with the lack of capital as the largest obstacle to its successful implementation. Even in a country such as South Africa, which faces severe inequality as well as developmental challenges, the benefits of using new technologies in secondary education cannot be ignored, especially within the context of EE.

The use of ICTs and GIS can greatly enhance the teaching of EE in South Africa, however, there are numerous problems experienced by educators in using these technologies. Such challenges include: a lack of access to resources, inadequate professional development or educator training programmes, as well as unrealistic beliefs and attitudes amongst educators [25]. An educator's ability to use technology will significantly influence his/her willingness to integrate ICTs into the classroom situation. If educators believe that their use of technology will benefit their students, they are more likely to use it [25]. 


\section{Methodology}

A mixed-methods approach was used in this study to use the strengths of both qualitative and quantitative research. The study group comprised of 69 Geography educators that taught at public secondary schools within the Gauteng Province of South Africa. The respondents within the sample group were selected utilising a convenience sampling method. Educators were contacted electronically via email and Google forms was employed as a data collection platform. The primary data collection used in this research study was a research survey in the form of a questionnaire.

The questionnaire itself is made up of three sections. The first section of the questionnaire asks general and demographic questions, such as the age of respondents and the highest educational qualifications the respondents achieved. The second section is based on EE in Geography in high school education and the third section is based on the use of technology for EE purposes. Both qualitative and quantitative based question are asked, allowing for various types of data and information to be acquired from the respondents, including opinion-based answers, as well as open-ended questions. Descriptive statistical methods were used to analyse the quantitative portion of the data collected. The results from the data collection are shown and discussed in the next section.

\section{RESULTS}

Firstly, examining the demographics of the study group, $59.4 \%$ of the respondents are males and the remainder females $(40.6 \%)$. The study group is mature in nature, with $94 \%$ of respondents over the age of 30 , indicating a degree of experience within the sample group - with $65.2 \%$ of respondents in the age group of 40-49. The average number of years respondents had taught Geography was 16 years, indicating that a large portion of the sample group would have taught multiple sets of curricula. As the respondents are experienced teachers, they could comment on EE in not only in Geography, but also in other subjects as just more than half (53.6\%) are teaching multiple subjects such as physical science, life science and life orientation. Furthermore, it was found that $45 \%$ of respondents had achieved an honours or a master's degree, indicating further specialisation within a particular field.

In order to understand and gauge the state of EE within secondary schools of South Africa, it was important to understand the views and attitudes of educators towards EE. With [2:95] stating "if educators are not environmentally literate themselves, then instilling knowledge, attitudes, skills, awareness and actions in learners will not be successful in achieving the goal of producing environmentally literate citizens". It was reassuring to find that the majority (98.6\%) of the respondents thought it was important to include EE within the school curriculum. The respondents recognise that there are serious environmental problems affecting the environment currently, and that these affect the quality of human lives. Numerous respondents identified that the environment is very much interlinked to the economy and our social environment. Respondents further expressed that EE allowed students to gain an appreciation for the environment around them.
All respondents agreed to the fact that EE should be integrated into school curricula but were split in whether it should be taught in multiple subjects or not. $68 \%$ of respondents thought it should be taught in subjects such as life orientation in addition to Geography, thus reaching a wider audience as life orientation is a compulsory subject for learners in the FET phase. In line with this, respondents were asked to indicate their level of knowledge regarding environmental problems, the answers to which are shown in Fig. 1.

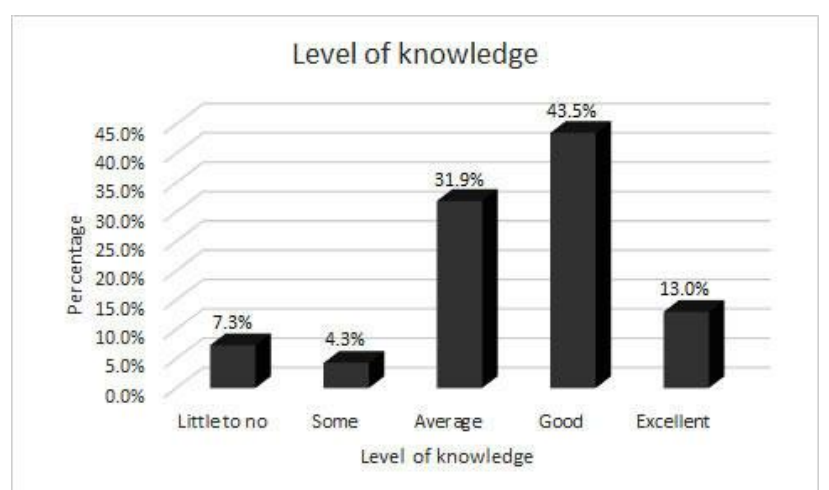

Fig. 1: Level of knowledge of environmental problems

Over half $(56.5 \%)$ of the respondents felt that they have either a good understanding or an excellent level of knowledge in respect of current environmental problems. However, $11.5 \%$ of respondents felt they have little to no knowledge or only some knowledge of environmental problems and 31.9\% indicating an average knowledge. As respondents are all Geography teachers and are expected to keep up to date with environmental problems and risks, this result is concerning. In a follow up question to this, respondents were asked whether they felt they had enough knowledge on EE to be able to teach it effectively, to which only $65 \%$ of respondents answered yes. This means a third of teachers do not have enough knowledge to teach EE. If educators feel they are not knowledgeable in terms of a particular subject, this will influence their confidence approaching the content in the classroom environment. When asked about whether there was enough EE content within the Geography curriculum, the majority of respondents (74\%) felt the current Geography curriculum does not cover enough EE content and is not sufficient to produce environmentally literate citizens, which is the primary goal of EE.

In line with the above, it is important to take note of the fact that only $34.8 \%$ of respondents felt that EE in its current form, as taught in South African secondary schools, plays an important role in producing more environmentally caring citizens. Respondents were queried what they felt were the greatest challenges in improving the current structures for $\mathrm{EE}$ within South Africa and the results are shown in Fig. 2. 


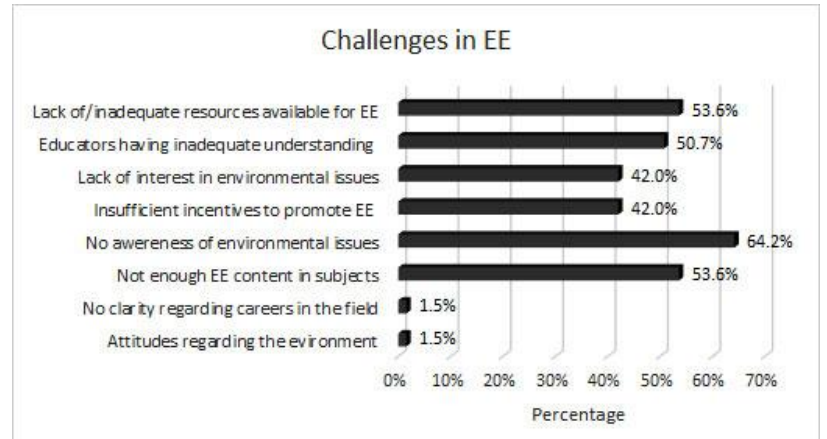

Fig. 2: Challenges in improving current structures for EE.

The lack of awareness of the extent of environmental issues in South Africa and around the world was identified as the greatest challenge by $64.2 \%$ of the respondents. This was followed by respondents indicating there is not enough EE content in the school subjects and the lack of or inadequate resources available for teaching EE, with $53.6 \%$ for both. Issues surrounding the availability of resources comes as no surprise especially within the context of South Africa where inequality is rampant.

Regarding the use of technology for EE purposes within South Africa, $85 \%$ of respondents indicated that there is a strong potential for GIS and ICTs to be used within the classroom for the purpose of EE. The higher the level of knowledge of an educator in respect of a particular subject or piece of equipment, the most likely (s)he would feel confident using it in the classroom. Fig. 3 illustrates the level of knowledge of GIS and ICT as indicated by respondents.

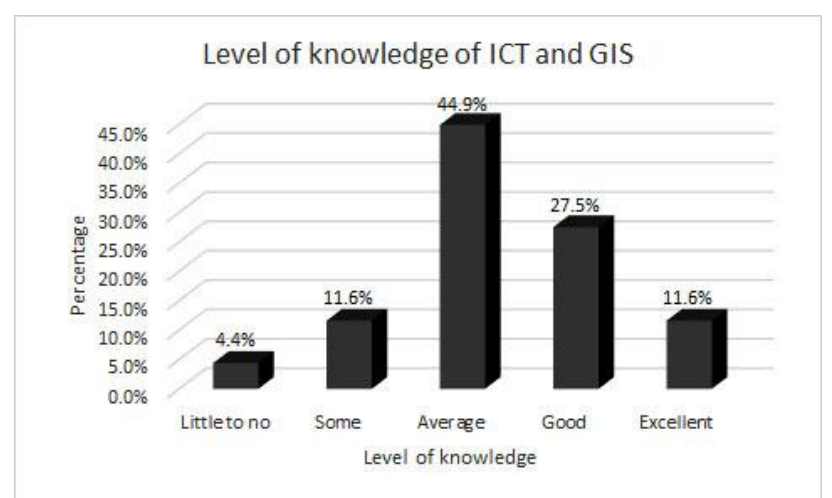

Fig. 3: Level of knowledge of GIS and ICT

Only $39.1 \%$ of teachers indicated that they have a good to excellent level of knowledge regarding the use of ICT and GIS. This result, together with $44.9 \%$ indicating an average level of knowledge, shows that there is a need for educators to be trained in the use of these in the classroom.

Although educators may be confident in approaching and utilising certain technologies for the teaching EE and other learning areas, they face certain barriers to using ITCs in the classroom. Such barriers are identified in Fig. 4.

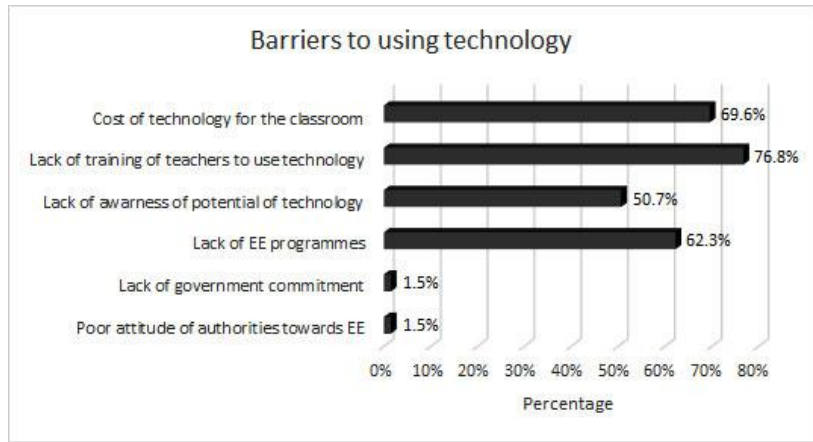

Fig. 4: Barriers to using ITCs in the classroom

Considering the sample group was mature in nature, it is no surprise that the lack of training for educators in the use of certain technologies was identified as the largest barrier, with $76.8 \%$. The second greatest barrier identified was the cost of the necessary technology needed (69.6\%). With great inequality in schools in South Africa, this result was not unexpected. If a school does not have capital for equipment such as computers and software, then educators cannot use technology in the teaching and learning in the classroom. The barriers that were identified by respondents are in line with those identified by [27] for implementing GIS in South African schools, namely money, support and time. Where technological resources are not available, students are at massive disadvantage. For example, GIS consists of both a theory and practical component, and without access to computers and software, no practical GIS can take place.

When queried if respondents were aware of the curriculum requirements of GIS within the South African national Geography curriculum, only $77 \%$ of respondents were aware of the requirements, whereas a further $20 \%$ having some idea of the requirements. A positive result was that the respondents viewed GIS as a technology that can enhance the learning of EE and Geography in the classroom. $81.2 \%$ of respondents viewed GIS as a tool that can encourage critical thinking amongst students, whereas $71 \%$ of respondents viewed GIS as a tool which can be used to encourage students to interact and question geographic information. Even though GIS has been part of the FET Geography curriculum since 2006, $88 \%$ of educators indicated that their learners struggled with this section of the syllabus.

The implementation GIS in schools has faced significant challenges and barriers and the results are very similar to the barriers identified for using ITCs in the classroom. The largest barrier identified by respondents for implementing GIS was that the resources required for GIS are not available at many schools due to the large financial requirements $(82.6 \%)$. This was closely followed by the training required to be able to teach GIS that is not always available or accessible and is often expensive (72.5\%). As GIS is a relatively new technology and the respondents are a mature group, the majority would not have received any GIS training in their teaching degree/diploma. These barriers illustrate the key issues of inequality, lack of further training and a lack of resources within secondary schools within Gauteng, South Africa. 


\section{CONCLUSION}

The implementation of EE across school curricula in South Africa has been particularly slow. Educators indicated that there is not enough EE content, not only in Geography, but also in other school subjects. Even though educators understood the importance of producing environmentally literate students, few recognised that they were championing $\mathrm{EE}$ within their own schools. The research showed there was a strong willingness amongst educators to be involved in the teaching of $\mathrm{EE}$ in the classroom. Educators and respondents within the study further strongly recognised the positive role that technology can play in enhancing the quality of their lessons to the benefit of their students.

However, numerous problems emerged from the research concerning the state of EE and the use of technology for EE teaching within Gauteng schools. Mainly is the lack of access to resources, especially access to technologies such as ICTs and GIS. Other significant barriers that were identified during the research are the lack of appropriate training for educators, the ineffectiveness of the current systems in place, as well as a lack of awareness as to the extent of environmental problems in South Africa and around the world. Even though EE has come a long way in South Africa, there is not enough EE content in the current curricula and use of technology for teaching EE is extremely limited.

\section{REFERENCES}

[1] Maluleke, N.N. 2005. The Impact of the National Environmental Education Policy Initiatives in South African Schools. M.A. Dissertation. Johannesburg: University of the Witwatersrand.

[2] Govender, K. 2011. Inclusion of Environmental Education in South Korean Schools. M.Sc. Dissertation. Pretoria: University of South Africa.

[3] UN (United Nations). 1992: Agenda 21. UNCED (United Nations Conference on Environment and Development). 3-14 June 1992. Rio de Jainero: United Nations.

[4] Hoegh-Guldberg, O. \& Bruno, J.F. 2010. The Impact of Climate Change on the World's Marine Ecosystems. Science, 328(5985), 1523-1528. https://doi.org/10.1126/science. 1189930

[5] Eneji, C.V.O.; Akpo, D.M. \& Edung, A.E. 2017. Historical Groundwork of Environmental Education (Fundamentals and Foundation of Environmental Education). International Journal of Continuing Education and Development Studies, 3(1), 110-123.

[6] Courville, K. 2011. Technology and its use in Education: Present Roles and Future Prospects. Recovery School District Technology Summit. 6-8th June 2011. Baton Rouge, Louisiana: Recovery School District Technology Summit.

[7] Le Grange, L. \& Reddy, C. 1997. Environmental Education and Outcomes-based Education in South Africa: A Marriage Made in Heaven? Southern African Journal of Environmental Education, 17, 12-18.

[8] Agnes, A. M. \& Nor, A. R. M. 2011. Implementation of Environmental Education: A Case Study of Malaysian and Nigerian Secondary Schools. 2010 International Conference on Biology, Environment and Chemistry, 28-30 December 2010. Hong Kong: Institute of Electrical and Electronic Engineers.

[9] Schudel, I. Le Roux, C. \& Sistika, H.C. 2008. Contextualizing Learning in Advanced Certificate in Education (Environmental Education) Courses: Synthesizing contexts and Experience. South African Journal of Education, 28(4), 1-13.

[10] Symmonds, A. 2008. Teacher Capacity Building: Skills Development through Environmental Education. Pretoria: National Biological Institute.
[11] Le Roux, C. \& Maila, W. 2004. Issues and Challenges Regarding Environmental Education Policy Implementation. Africa Education Review, 1(2), 234-244. https://doi.org/10.1080/18146620408566282

[12] Department of Basic Education. 2011. Curriculum and Assessment Policy Statement: Grades 10-12: Geography. Pretoria: Department of Basic Education.

[13] Disinger, J.F. 1985. What research says: Environmental Education's definitional problem. School Science and Mathematics, 85(1), 59-68. https://doi.org/10.1111/j.1949-8594.1985.tb09596.x

[14] Stegner, W. 1990. It All Began with Conservation. Smithsonian, 21(1), 35-43.

[15] Stapp, W.; Havlick, S.; Bennett, D.; Bryan, W.; Fulton, J.; McGregor, J.; Nowack, P.; Swan, J. \& Wall, R. 1969. The Concept of Environmental Education. The Journal of Environmental Education, 1(1), 30-31. https://doi.org/10.1080/00139254.1969.10801479

[16] UNESCO-UNEP. 1976. The Belgrade Charter. UNESCO-UNEP Environmental Education Newsletter, 1 (1).

[17] Mosidi, S.M. 1999. Environmental Education in Curriculum 2005: A Case Study in the Northern Cape. M.A. Dissertation. Johannesburg: Rand Afrikaans University.

[18] Gough, A. \& Gough, N. In Press: Environmental Education. In Kridel, C (Ed.). The SAGE Encyclopedia of Curriculum Studies. New York: Sage Publications.

[19] Irwin, P.R. 1990. The Concept of Environmental Education and the Development of Environmental Education in South Africa. Keynote address delivered at the Annual Workshop and AGM of EEASA.

[20] South Africa. Department of Education. (1995). White Paper on Education. Government Gazette. (Vol. 375, No. 45621).

[21] Mokhele, M.L. 2011. Integrated Environmental Teaching in South Africa: An Impossible Dream? Perspectives in Education, 29(4), 78-86.

[22] Mohammed, I.I.S. 2016. The Implementation of Environmental Education at Muslim Schools in Gauteng: A Case Study. M.A. Dissertation. University of South Africa: Pretoria.

[23] Kerski, J.J.; Demirci, A. \& Milson, A.J. 2013. The Global Landscape of GIS in Secondary Education. Journal of Geography, 112(6), 232-247. https://doi.org/10.1080/00221341.2013.801506

[24] Blažek, M.; Lána, M.; Blažek, V. \& Dvořák, J. 2017. Information Technologies in Teaching Geography from the Teacher's Point of View. In Karvánková, P.; Popjaková D., Vančura M. \& Mládek J. (Eds.). Current Topics in Czech and Central European Geography Education. Cham (Switzerland): Springer International Publishing, 169-186. https://doi.org/10.1007/978-3-319-43614-2_10

[25] Nkula, K. \& Krauss, K. 2014: ICTs for Inclusive Communities in Developing Societies. Proceedings of the 8th International Development Informatics Association Conference. Port Elizabeth: International Development Informatics Association.

[26] Demirci, A.; Kerski, J.J. \& Milson, A.J. 2013. The Global Landscape of GIS in Secondary Education. Journal of Geography, 112(6), 232-247. https://doi.org/10.1080/00221341.2013.801506

[27] Breetzke, G.D., Eksteen, G. \& Pretorius, E. 2011. Paper-Based GIS: A Practical Answer to the Implementation of GIS Education in Resource-poor Schools in South Africa. Journal of Geography, 110(4), 148-157.

[28] Hew, K. F. and Brush, T. 2007. Integrating Technology into K-12 Teaching and Learning: Current Knowledge Gaps and Recommendations for Future Research. Educational Technology Research and Development, 55(3), 223-252. https://doi.org/10.1007/s11423-006-9022-5 